\title{
Análise do Planejamento Tributário na Perspectiva da Gestão
}

\author{
Francisco Fabiano Valença da Silva ${ }^{1}$ : Maria Erilúcia Cruz Macêdo ${ }^{2}$
}

\begin{abstract}
Resumo: Esta pesquisa objetiva analisar como ocorre o planejamento tributário nas empresas, na perspectiva da gestão, tendo em vista que o administrador é o grande responsável por todo o processo de planejamento dentro da empresa. Para verificação do problema proposto foi realizada uma pesquisa aplicada, descritiva, Bibliográfica, com abordagem qualitativa. Os resultados apontam que as organizações de forma geral não realizam o planejamento tributário, nem tampouco o seu contador participa ou realiza esse tipo de planejamento. Salientase que o Planejamento tributário é capaz de contribuir de forma significativa com a redução dos custos da empresa, por meio de um estudo detalhado não somente dos tributos que deverão ser pagos, como também da escolha do regime de tributação mais adequado e da análise minuciosa dos demonstrativos e da própria legislação.
\end{abstract}

Palavras- Chave: Planejamento. Tributos. Gestão

\section{Analysis of Tax Planning in the Management Perspective}

\begin{abstract}
This research aims at analyzing how tax planning occurs in companies from a management perspective, considering that the administrator is responsible for the entire planning process within the company. To verify the proposed problem, an applied, descriptive, Bibliographic research was carried out with a qualitative approach. The results indicate that organizations generally do not carry out tax planning, nor does their accountant participate in or carry out this type of planning. It should be noted that Tax Planning is able to contribute significantly to the reduction of company costs, through a detailed study not only of the taxes to be paid, but also of the choice of the most appropriate tax regime and analysis and the legislation itself.
\end{abstract}

Keywords: Planning. Taxes. Management

\section{Introdução}

Uma boa gestão tributária dentro da organização é um dos principais fatores para o sucesso de qualquer negócio no Brasil, tendo em vista que o país é um dos que possuí umas das cargas maiores cargas de tributos do mundo. A falta de preparo para lidar com os altos tributos faz com que uma grande parte desses empreendimentos atuem na informalidade ou recorram a práticas ilícitas de sonegação fiscal para manter as suas atividades e sobreviver, o que é prejudicial para a sociedade, para o mercado, para a economia e para a própria empresa, a qual terá dificuldades de crescimento.

\footnotetext{
${ }^{1}$ Graduando do Curso de Ciências Contábeis, UNILEÃO. valencacontabilidade2@ gmail.com

${ }^{2}$ Mestranda em Gestao de Negócios de Turisticos - UECE. Docente da UNILEÃO. erilucia@ leaosampaio.edu.br
} 
Observa-se também que boa parte dos gestores das micro e pequenas empresas, possuem muitas dificuldades na realização dessa parte financeira da empresa, principalmente na realização de um planejamento tributário eficaz que seja favorável ao seu negócio.

O planejamento tributário é uma ferramenta essencial dentro da gestão financeira da empresa, tendo em vista que quando realizado de forma correta pode diminuir custos, e aumentar a capacidade produtiva e o desenvolvimento de vantagem competitiva para a organização. O administrador é o grande responsável por desenvolver o processo de planejamento dentro da empresa, inclusive o planejamento tributário. Dessa forma, questionase como os gestores realizam um planejamento tributário de forma a alavancar o seu negócio.

A pesquisa objetiva analisar como ocorre o planejamento tributário na perspectiva da gestão, tendo em vista que o administrador é o grande responsável por todo o processo de planejamento da empresa. Tendo os seguintes objetivos específicos: Verificar como o gestor e a contabilidade planejam os tributos na organização; observar a existência da integração e comunicação entre o gestor e a contabilidade durante a realização do planejamento tributário; constatar a importância do contador da empresa como assessor no planejamento tributário.

\section{Conceito de Tributo}

Antes de conceituar o que seria o planejamento tributário faz-se necessário, entender o que são tributos e o seu peso dentro de uma empresa. Com o passar dos anos as pessoas vêm mudando a concepção de tributo, deste modo vários autores fazem comparações e análises da sua evolução. É comum identificar opiniões adversas na história e que causa impactos interessantes.

De acordo com Rezende et al (2010, p.11) os tributos:

Confundem-se com a história antiga da criação do Estado, pois além do intuito de custeio de grandes obras institucionais, administrativas públicas e de força militar, promoviam também a ideia de que o soberano era um ser divino e de necessidades luxuosas. Até na extração de frutos da terra eram cobrados tributos, devido a essas pertencerem aos soberanos.

A palavra tributo tem sua origem no verbo latino tribuere (tribuo - is, ere, tribui, tributum), tendo o significado de dividir ou repartir entre as tribos, desta maneira sendo a carga pública a ser distribuída entre o povo (tribo), assim, se tornando uma exigência de autoridade 
para os seus subordinados, tendo o interesse de compartilhar e sanar as necessidades coletivas. (HEIN et al, 2003).

$\mathrm{O}$ artigo $\mathrm{n}^{\circ} 3$ do Código Tributário Nacional - (CTN) define de forma legal o tributo como sendo toda prestação pecuniária compulsória, em moeda corrente ou cujo valor se possa exprimir, que não se constitua sanção de ato ilícito. (BRASIL,2017)

A evolução histórica do tributo leva a perceber que houve uma mudança, mesmo que lenta, na concepção de tributo, pois este deixa de ser fruto do poder arbitrário do Estado para constituir-se como instrumento jurídico gerador de receita pública, legislado pela lei ordinária. O desenvolvimento do tributo está ilustrado na transformação do aspecto rude em uma forma mais aberta, concretizada na lei ordinária. Atualmente, o tributo nada mais é, do que uma ferramenta normatizada de captação de receita para a manutenção e desenvolvimento do interesse público.

\section{Legislação Tributária}

O Art.96 da Lei n 5.172/66 (Código Tributário Nacional - CTN) define legislação Tributária como sendo: "Art.96. A expressão "legislação tributária" compreende as leis, os tratados e as convenções internacionais, os decretos e as normas complementares que versem, no todo ou parte, sobre tributos e relações jurídicas a eles pertinentes”. (BRASIL, 2011)

Desde a atualização do Sistema Tributário Nacional, ocorrida a partir da Constituição Federal de 1988, as regras e alterações expedidas definiram novos campos de incidência dos tributos, além da mudança na forma de distribuição da arrecadação auferida entre União, Estados e Municípios. Isso vem levantando entre os especialistas, a necessidade de nova reforma tributária, para definição de uma melhor divisão das receitas arrecadadas. (OLIVEIRA, 2005).

\section{Elementos Fundamentais do Tributo}

Segundo Oliveira et al (2005) a obrigação tributária surge quando, por meio de uma relação jurídica, determinada pessoa (credor) pode exigir de outra (devedor) uma prestação (objeto), em decorrência de determinação prévia legal ou de manifestação de vontade (como, por exemplo, o pagamento de prêmio em um concurso). 
Os tributos possuem características próprias que dependem de fatores relacionados a sua legislação vigente para serem cobrados. De acordo com Oliveira et al (2005, p.28) a obrigação tributária “ é a relação de Direito Público na Qual o Estado (sujeito ativo) pode exigir do contribuinte (sujeito passivo) uma prestação (objeto) nos termos e nas condições descritos na lei (fato gerador) ".

\title{
A Lei
}

É o principal elemento da obrigação, pois cria os tributos e determina as condições de sua cobrança. Contudo, assume, em um sistema jurídico, formas diferentes de expressão, a partir de um texto fundamental (Constituição), as regras ordinárias de convivência (leis em sentido restrito). (OLIVEIRA, 2005).

A lei também traz controvérsias quando o assunto é o governo, pois este, através de edição de Medidas provisórias, poderia majorar tributos, que enquanto não apreciadas pelo Congresso Nacional, têm força de Lei. Porém decorridos 45 dias de sua edição, se torna ineficaz, sendo vedada a reedição após esse prazo. (OLIVEIRA, 2005).

\section{Objeto}

De acordo com Oliveira et al (2005, p.29):

\begin{abstract}
O objeto representa as Obrigações que o sujeito passivo (contribuinte) deve cumprir, segundo as determinações legais. Basicamente, as prestações consistem em: pagamento do valor em dinheiro referente ao tributo devido ou à multa imposta por não-atendimento à determinação legal (obrigação principal) ou cumprimento de formalidades complementares, destinadas a comprovar a existência e os limites da operação tributada e a exata observância da legislação aplicável que caracterizam as obrigações acessórias.
\end{abstract}

Os contribuintes estão sujeitos a algumas obrigações, sejam elas principais ou acessórias, sendo identificadas em algumas práticas como: Declarações de rendimentos, preenchimento de formulários, escrituração de livros fiscais, etc. (FABRETTI, 2011).

\section{Fato Gerador}

Rezende et al (2010, p.50), definem fato gerador como "a concretização da hipótese de incidência, ou seja, a materialização da situação descrita em lei”. 
O CTN define fato gerador nos arts. 114 e 115:

Art. 114. Fato gerador da obrigação principal é a situação definida em lei como necessária e suficiente à sua ocorrência.

Art. 115. Fato gerador da obrigação acessória é qualquer situação que, na forma da legislação aplicável, impõe a prática ou a abstenção de ato que não configure obrigação principal.

O fato gerador é o responsável por concretizar uma obrigação principal, sempre de natureza pecuniária, que pode ser identificado na emissão de notas fiscais, escrituração de livros fiscais, registro de funcionários, inscrição no Cadastro Nacional de Pessoa Jurídica (CNPJ), etc. (FABRETTI, 2006).

\section{Base de Cálculo}

Concretizado o fato gerador, é de interesse do contribuinte, ou responsável, identificar meios de aplicação das determinações legais para definição da base de cálculo do imposto e alíquota aplicável. Fabretti et al (2011, p.41) define base de cálculo como sendo "o valor sobre o qual é aplicada a alíquota (percentual) para apurar o valor do tributo a pagar".

A base de cálculo é definida em lei complementar (art. 146 da CF), esta deve ser observada e analisada para aplicação coesa dos critérios presentes e pertinentes a cada tributo de forma específica. É de suma importância conhecer as características de cada tributo, assim facilitando o cálculo e definição do valor a ser recolhido (FABRETTI, 2006).

\section{Alíquota}

Para Rezende et al (2010, p.52) alíquota é "o valor ou percentual definido em lei que, aplicado à base de cálculo, determina o montante do tributo a pagar".

É importante conhecer as alíquotas aplicáveis e suas determinações legais, deste modo eliminando a perda de dinheiro desnecessária. $\mathrm{O}$ conhecimento da lei leva o contribuinte a definir planos que identifique oportunidades de diminuição da carga tributária incidente. Desta forma se torna essencial analisar as leis regentes de cada tributo, facilitando a incorporação de práticas lícitas que levem a diminuição da carga tributária e elevem o patrimônio dos contribuintes. (FABRETTI, 2011). 


\section{Contribuinte ou Responsável}

Segundo Rezende e Pereira (2010, p.54), denomina-se contribuinte aquele que obtenha relação pessoal e direta com o fato gerador da obrigação. Já o responsável é caracterizado pela indicação da lei de pagar o tributo. Esses também podem ser chamados de sujeito passivo, a depender da relação destes com o fato gerador da obrigação.

\section{Planejamento Tributário}

Para Young (2006 p.91): “O planejamento tributário é o conjunto de condutas, comissivas ou omissivas, da pessoa física ou jurídica, realizadas antes ou depois da ocorrência do fato gerador, destinadas a reduzir, mitigar, transferir ou postergar legal e licitamente os ônus dos tributos".

Fabretti (2005) afirma que "o planejamento tributário é a atividade preventiva que estuda a priori os atos e negócios jurídicos que o agente econômico (empresa instituição financeira, cooperativa, associação, etc.)". O autor ainda comenta que a finalidade do planejamento tributário é reduzir a carga tributária obtendo maior economia fiscal possível, sendo por meio do planejamento que a empresa se organiza, visando reduzir custos com tributos.

Rezende (2010), evidencia que o planejamento tributário deve ser visto como o estudo das alternativas lícitas para que se possa encontrar, dentro dos ditames da lei, alternativas menos onerosas quanto aos aspectos tributários para o reconhecimento dos tributos por parte das empresas.

Para Oliveira et al $(2005$, p.38) "o contador tem principalmente nas atividades de planejamento tributário a grande oportunidade de dar enormes contribuições à alta direção da empresa.

Com a constante variação de normas e leis que regem os tributos e até mesmo as rotinas tributárias das empresas, o planejamento tributário deve se mostrar apto para preencher as lacunas e sanar as deficiências da organização. Essa mudança tempestiva de cenário tributário leva a criação de novas ferramentas que possam auxiliar na identificação e mensuração de 
problemas contábeis e fiscais, com isso, entende-se que se faz necessário a frequente injeção de estratégias que levem a redução de custos e despesas. (OLIVEIRA et al, 2005).

Oliveira et al (2005, p.39) ressalta que "planejar é escolher, entre duas ou mais alternativas lícitas de formalização jurídica de determinada operação, antes da ocorrência do fato gerador, para que o contribuinte possa optar pela que apresente o menor ônus tributário." A partir dessa colocação pode-se inferir que todo e qualquer meio, sendo que não fira a lei, que tenha o propósito de diminuir a carga tributária pode ser considerado planeamento tributário, ou ainda, elisão fiscal.

\section{O Papel dos Gestores no Planejamento Tributário}

Dentre as inúmeras atividades que os gestores desempenham dentro da empresa a ação de planejar é essencial para que todas as outras ações possam se desenvolver dentro do ambiente organizacional. Dentro da área financeira, sem um planejamento eficiente, dificilmente a organização conseguirá manter a sua produção, e consequentemente atingir aos seus objetivos. Nesse contexto, é extremamente necessário que os administradores também executem um planejamento tributário, para que possam dimensionar o quanto gastam em tributos, e poderem desenvolver maneiras de realizar a elisão fiscal.

Lopes (2017) comenta que a gestão de tributos é um dos fatores primordiais para o sucesso de qualquer organização. Conforme o autor no Brasil são criadas cerca de trinta e sete novas normas tributárias a cada dia (segundo dados do Instituto Brasileiro de Planejamento Tributário - IBPT). Dessa forma, os gestores devem estar, acima de tudo, muito bem informados para que possam pagar o mínimo de tributos possíveis, e com isso diminuir os custos da empresa.

Os grandes empresários normalmente costumam realizar esse tipo de planejamento, tendo em vista o grande número de produtos e/ou serviços comprados e vendidos ao longo do exercício financeiro. Contudo, os micro e pequenos empresários, por não terem um grande faturamento anual acabam não realizando nenhuma espécie de planejamento tributário, passando essa responsabilidade apenas para o contador. Lopes (2017) aborda que Especialmente nas micro e pequenas empresas, onde os gestores (que, normalmente, são os próprios empresários) não possuem, na maioria dos casos, o conhecimento necessário da legislação tributária, o contador deve voltar esforços para expor com clareza as opções disponíveis para a tomada de decisão, indicando as vantagens e desvantagens de cada caminho. 
Outro condicionante a ser mencionada é a falta de orientação dos empresários, os quais muitas vezes não realizam sequer um planejamento tributário adequado.

Conforme Costa (2012) pontua um dos maiores problemas que acontecem dentro das micro e pequenas empresas é a ausência de conhecimento dos gestores sobre a importância das informações contábeis, e a distorção da função da contabilidade e do papel do contador, em especial ao que está relacionado à Legislação Tributária, esquecendo-se que a contabilidade não está restrita apenas ao fisco, e que seu objetivo principal é o fornecimento de informações para a tomada de decisão.

A falta de preparo para lidar com os altos tributos faz com que uma grande parte desses empreendimentos atuem na informalidade ou recorram a práticas ilícitas de sonegação fiscal para manter as suas atividades e sobreviver, o que é prejudicial para a sociedade, para o mercado, para a economia e para a própria empresa, a qual terá dificuldades de crescimento.

Segundo Santos (2009) cabe ao administrador analisar a relação/custo benefício para a empresa, optando pelas medidas viáveis, em conformidade com o enquadramento da mesma. Um bom planejamento tributário pode proporcionar ao gestor uma visão sistêmica em relação ao estado patrimonial da empresa, assegurando resultados positivos e consideráveis, em conformidade com os aspectos legais da elisão fiscal.

Para que o empreendimento se desenvolva corretamente é preciso que a gestão tributária seja implementada desde o seu nascimento, ainda na escolha do regime de tributação, pois, ao contrário do que crê o senso comum, nem sempre a opção pelo Simples Nacional é a mais vantajosa.

Outro aspecto vital para uma boa gestão tributária é a organização. Lopes (2017) comenta que para uma empresa possa ser considerada realmente organizada não basta apenas manter em boa ordem os seus documentos. A organização, em um sentido mais amplo, abrange também a "organização contábil”", com a manutenção de uma escrituração completa (ainda que simplificada, no caso das micro e pequenas empresas) e que reproduza fielmente a situação patrimonial, econômica e financeira daquela entidade.

\section{A contabilidade e a relação com o planejamento tributário organizacional}

Carvalho (2017) comenta que dentro do contexto das micro e pequenas empresas o contador atua como uma peça chave na redução da mortalidade, e na diminuição dos custos organizacionais. Antes que a empresa se descontinue ele surge para realizar uma reeducação 
tributária de seus clientes, sendo o principal responsável pela geração de informações sobre o patrimônio da empresa, evidenciando sua situação econômica e financeira. Porém, não é suficiente apenas o levantamento de dados para que os impostos sejam apurados e as guias de recolhimento geradas; devendo esse profissional ter um papel significativo na construção de uma rotina de gestão de tributos.

Martins (2012) comenta que o papel do contador na sociedade tem evoluído significativamente, deixando de ser visto apenas como um escriturador contábil, para ser responsável por emitir informações que irão auxiliar no processo decisório das organizações. Ressalta-se que, para assumir esse papel, o contador deve estar preparado para encarar esse desafio. Dessa forma, é importante que o profissional da contabilidade esteja sempre atualizado, atento às mudanças repentinas desse confuso cenário tributário brasileiro.

Contudo, a responsabilidade de realização desse planejamento, bem como colocá-lo em prática, não é uma tarefa que pertence ao profissional de contabilidade unicamente, uma vez que, embora ele seja indispensável ao processo decisório da empresa, não toma decisões diretas no âmbito empresarial, cabendo ao gestor tal função.

Dessa forma, o contador conceitualmente deixou de ser relacionado apenas ao pagamento de tributos, para ser responsável em fornecer informações para o processo de decisão das organizações. Onde por meio dos seus conhecimentos e habilidades, contribui para que essas empresas tomem as decisões mais acertadas, colaborando ainda com o aumento dos lucros e da competitividade.

\section{Metodologia}

Com o intuito de analisar o planejamento tributário na perspectiva da gestão foi realizada uma pesquisa exploratória, com característica descritiva e abordagem Qualitativa.

Do ponto de vista de sua natureza esta pesquisa classifica-se como aplicada, que conforme Andrade (2007) visa gerar conhecimentos a aplicação prática dirigida à solução de problemas específicos.

Quanto à abordagem adotada foi do tipo qualitativo, na busca de analisar corretamente os dados coletados. Para Denzin e Lincoln (2006), a pesquisa qualitativa envolve uma abordagem interpretativa onde os pesquisadores estudam as coisas em seus cenários naturais, tentando compreender as pessoas e o ambiente na qual estão inseridas. Segundo Gil (2007, p. 17), pesquisa é definida como o: 
(...) procedimento racional e sistemático que tem como objetivo proporcionar respostas aos problemas que são propostos. A pesquisa desenvolve-se por um processo constituído de várias fases, desde a formulação do problema até a apresentação e discussão dos resultados.

Do ponto de vista de seus objetivos a pesquisa se classifica como exploratória e descritiva. A Pesquisa Exploratória é um tipo de investigação que mesmo já havendo diversas pesquisas sobre o assunto, não se verifica existência de estudos sobre o ponto de vista pelo qual a pesquisa abordará (VERGARA, 2004). Visando assim, proporcionar uma maior compreensão do fenômeno estudado (ANDRADE, 2007).

A pesquisa descritiva conforme Gil (2010) visa descrever as características de determinada população ou fenômeno ou o estabelecimento de relações entre variáveis. Envolvendo o uso de técnicas padronizadas de coleta de dados como questionário e observação sistemática. Assumindo, em geral, a forma de Levantamento. Acevedo (2007) fala que a pesquisa descritiva permite compreender as relações entre os construtos envolvidos no fenômeno em questão.

No que diz respeito aos procedimentos técnicos, a pesquisa classifica-se como bibliográfica com estudo de caso. Segundo Lakatos e Marconi (1996), o intuito da pesquisa bibliográfica é colocar o cientista em contato com o que foi produzido sobre determinado assunto através de livros, revistas e artigos já publicados. Na percepção de Gil (1994, p. 71) "A principal vantagem da pesquisa bibliográfica reside no fato de permitir ao investigador a cobertura de uma gama de fenômenos muito mais ampla do que aquela que poderia pesquisar diretamente". Já no que se volta ao estudo de caso, o mesmo, na percepção de Yin (2005), é adequado quando se pretende investigar o como e o porquê de um conjunto de eventos contemporâneos. Para Gil (2009) o estudo de caso tem o propósito de explorar situações da vida real cujos limites não estão claramente definidos, preservar o caráter unitário do objeto estudado, descrever a situação do contexto em que está sendo feita uma determinada investigação, formular hipóteses e explicar as variáveis causais de determinado fenômeno em situações complexas que não permitam o uso de levantamentos e experimentos.

\section{Considerações Finais}

Com o desenvolvimento desta pesquisa pode-se perceber a importância do desenvolvimento de um planejamento tributário nas empresas. Também foi observado que o 
contador não pode atuar apenas como agente que contabiliza tributos e realiza obrigações acessórias, não participando juntamente com o gestor para a elaboração de um planejamento tributário capaz de reduzir custos e promover vantagem competitiva para a organização.

O planejamento tributário é uma ferramenta indispensável para a gestão financeira das organizações, tendo em vista que quando realizado de forma correta pode diminuir custos, e aumentar a capacidade produtiva e o desenvolvimento de vantagem competitiva para a organização. O administrador é o grande responsável por desenvolver o processo de planejamento dentro da empresa, inclusive o planejamento tributário, o papel do contador é fundamental para auxiliar, com as informações úteis, a tomada de decisão.

Salienta-se que o Planejamento tributário é capaz de contribuir de forma significativa com a redução dos custos das empresas, por meio de um estudo detalhado não somente dos tributos que deverão ser pagos, como também da escolha do regime de tributação mais adequado e da análise minuciosa dos demonstrativos e da própria legislação. Mas para que esta ferramenta ocorra de maneira satisfatória, o administrador e o contador da empresa devem atuar conjuntamente e estabelecerem um plano eficaz que vão em direção a melhorar a gestão fiscal e tributária da empresa.

Tendo em vista a importância dessa temática para o contexto das micro e pequenas empresas sugere-se a realização de novos estudos voltados não somente para a concepção dos gestores, mas também para os profissionais de contabilidade, suas perspectivas e atitudes diante do planejamento tributário nessas organizações, frente aos gestores e proprietários desses empreendimentos.

\section{Referências}

ACEVEDO, Claudia Rosa. Monografia no curso de administração: guia completo de conteúdo e forma inclui normas atualizadas da ABNT, TCC, TGI, trabalhos de estágios, MBA, dissertações e teses. 3 ed. São Paulo: Atlas, 2007.

ANDRADE, Maria Margarida de. Introdução à metodologia do trabalho científico: elaboração de trabalhos na graduação. 8. ed. São Paulo: Atlas, 2007.

BARDIN, L. Análise de Conteúdo. Lisboa, Portugal: Edições 70, LDA, 2009

BRASIL. Código de Tributário Nacional. Lei $\mathrm{n}^{\circ}$ 5. 172, de 25 de Outubro de 1966. Disponível em:<http://www.receita.fazenda.gov.br/Legislacao/CodTributNaci/ctn.htm.> Acesso em: 27 de novembro de 2017 
CARVALHO, C.L. Planejamento tributário nas micro e pequenas empresas. Disponível em: http://www.crcba.org.br/submissaodetrabalhos/arquivos/b70fcabae1.pdf $>$. Acesso em: 28 de novembro de 2017

COSTA, Daniel Fonseca. $O$ controle e as informações contábeis nas pequenas empresas: um estudo na cidade de Formiga, 2012. 112 p. Dissertação (Mestrado em Ciências Contábeis). Universidade Vale do Rio Verde. UNINCOR, 2012

DENZIN, N. K. e LINCOLN, Y. S. Introdução: a disciplina e a prática da pesquisa qualitativa. In: DENZIN, N. K. e LINCOLN, Y. S. (Orgs.). O planejamento da pesquisa qualitativa: teorias e abordagens. 2. ed. Porto Alegre: Artmed, 2006. p. 15-41.

FABRETTI, Láudio Camargo. Fusões, Aquisições, Participações e Outros Instrumentos de Gestão de Negócios: Tratamento Jurídico, Tributário e Contábil. São Paulo: Atlas, 2005.

Láudio Camargo. Prática Tributária da Micro, Pequena e Média Empresa. $6^{\circ}$ ed. revisada e atualizada, São Paulo, Atlas, 2006.

GIL, A. C. Como elaborar projetos de pesquisa. 4. ed. São Paulo: Atlas, 2009.

HEIN, André Fernando e PAETZOLD, Márcio Dorinel Hermes, Planejamento Tributário com Ênfase em Tributos Federais. Marechal Cândido Rondon: 2003. 113p. Monografia de Graduação Unioeste.

LAKATOS, Eva Maria e MARCONI, Marina de Andrade. Técnicas de pesquisa: planejamento e execução de pesquisas, amostragens e técnicas de pesquisas, elaboração, análise e interpretação de dados. 3. ed. São Paulo: Atlas, 1996.

Eva Maria. Fundamentos de metodologia científica. 7. ed. São Paulo: Atlas, 2010.

LOPES, André Charone Tavares Lopes. O papel do contador na gestão tributária dos pequenos empreendimentos. Disponível em: <https://www.classecontabil.com.br/artigos/o-papel-do-contadorna-gestao-tributaria-dos-pequenos-empreendimentos> Acesso em 15 de novembro de 2017

OLIVEIRA, Luís Martins; CHIEREGATO, Renato; HERNANDEZ, José; GOMES, Marliete Bezerra. Manual de Contabilidade Tributária. $4^{\circ}$ ed. São Paulo, Atlas, 2005.

PRADO, Eliane Cristina Pires. O papel e a atuação do contador tributário. Disponível em: < http://www.pgsskroton.com.br/seer/index.php/rcger/article/viewFile/1611/1543> Acesso em: 27 de novembro de 2017

REZENDE, Amaury José; PEREIRA, Carlos Alberto; ALENCAR, Roberta Carvalho. Contabilidade Tributária: Entendendo a lógica dos tributos e seus reflexos sobre os resultados das empresas. São Paulo, Atlas, 2010.

RIBEIRO, Elisa Antônia. A perspectiva da entrevista na investigação qualitativa. Evidência: olhares e pesquisa em saberes educacionais, Araxá/MG, n. 04, p.129-148, maio de 2008.

ROSA, Maria Virgínia de Figueiredo Pereira do Couto; ARNOLDI, Marlene Aparecida Gonzalez Colombo. A entrevista na pesquisa qualitativa: mecanismos para a validação dos resultados. Belo Horizonte: Autêntica Editora, 2006. 
VERGARA, Sylvia Constant. Relatórios e projetos de pesquisa em administração. 5 ed. São Paulo, Atlas, 2004.

YIN, R. K. Estudo de caso: planejamento e métodos. 3. ed. Porto Alegre: Bookman, 2005.

YOUNG, Lúcia Helena Briski. Planejamento Tributário: Fusão, Cisão e Incorporação. Curitiba: Jaruá, 2006.

ZANLUCA, Júlio César. A importância da gestão tributária nas empresas. Disponível em: < http://www.portaltributario.com.br/artigos/gestaotributaria.htm> Acesso em 27 de novembro de 2017

\section{Como citar este artigo (Formato ABNT):}

SILVA, Francisco Fabiano Valença da; MACÊDO, Maria Erilúcia Cruz. Análise do Planejamento Tributário na Perspectiva da Gestão. Id on Line Rev.Mult. Psic., 2019, vol.13, n.43, p. 627-639. ISSN: 1981-1179.

Recebido: 22/11/2018;

Aceito: 26/11/2018 